\title{
A imagem da moda muito além da sociedade do espetáculo: cultura visual e a formação docente em Artes Visuais ${ }^{1}$
}

Jociele Lampert ${ }^{2}$

\section{Resumo:}

Este estudo objetiva averiguar alguns embates na formação docente em Artes Visuais partindo das tensões entre a cultura visual, as Artes Visuais e a Educação (enquanto formação docente). Desta forma, ampara-se em uma reflexão teórica da educação para a compreensão crítica da arte e no que confere a contemporaneidade aborda-se Debord (1997). A moda é um ponto articulador na cultura visual e também se constitui como elemento agenciador dos estudos culturais na contemporaneidade. Assim, a abordagem do sistema estético da moda em contra ponto com as Artes Visuais, pode sugerir a construção de uma reflexão crítica sobre a sociedade em que vivemos.

Palavras-chave: Educação, Cultura Visual, Moda.

\begin{abstract}
:
This objective study to inquire some you strike in the teaching formation in Visual Arts leaving of the tensions between the visual culture, the Visual Arts and the Education (while teaching formation). Of this form, it is supported in a theoretical reflection of the education for the critical understanding of the art and in that it confers the contemporaneidade approaches Debord (1997). The fashion is a articulador point in the visual culture and also it consists as element agent of the cultural studies in the contemporaneidade. Thus, the boarding of the aesthetic system of the fashion in against point with the Visual Arts, can suggest the construction of a critical reflection on the society where we live. Key-words: Education, Visual Culture, Fashion.
\end{abstract}

A temática do trabalho inclina-se a discutir os conceitos de cultura, identidade, diferença, bem como, os conceitos de representação social que 0 receptor/espectador/leitor traz consigo. A pesquisa pauta-se sobre a seguinte

\footnotetext{
${ }^{1}$ Pesquisa atualmente desenvolvida no Doutorado em Artes Visuais na ECA - USP na linha de pesquisa de Ensino da Arte sob orientação da prof. Dra Ana Mae Barbosa.

${ }^{2}$ Doutoranda em Artes Visuais pela ECA - USP; Professora efetiva no Dep. de Artes Plásticas UDESC; Mestre em educação pela UFSM - RS (2005); Bacharel e Licenciada em Desenho e Plástica ambos pela UFSM - RS; Membro pesquisador do GEPAEC/UFSM - Grupo de Estudo e Pesquisa em Arte, Educação e Cultura e do Grupo de Pesquisa em Arte e educação CEART/UDESC, ambos diretório CNPq)
} 
hipótese: se a moda faz parte da sociedade do espetáculo, bem como da cultura visual, poderá ser passível de ser articulada com o conteúdo no Ensino da Arte, para então ser mediada na construção do conhecimento desenvolvido em sala de aula de forma contextualizada?

Trata-se de uma proposição para que o professor de Artes visuais entrelace em sua prática educativa conteúdo e contexto, percebendo-se como 'mediador' de um conteúdo que seja significativo para o aluno. Não seria apenas abordar a moda como uma temática banal, mas sim usá-la como objeto/ou mesmo, como um fio condutor desenvolvendo um trabalho de pesquisa em Artes Visuais. O que se busca refletir é como o educador media a aprendizagem a partir do estabelecimento de relações entre obras e seus contextos de produção.

A cultura visual é significada pelo contexto da visualidade contemporânea, ou seja, cultura visual são as conexões entre arte popular e arte erudita e outras formas de produção e comunicação visual, presentes na contemporaneidade.

Nesse sentido a cultura visual torna-se um campo emergente de pesquisa transdisciplinar e transmetodológica que estuda a construção da experiência visual enfatizada pela visualização do cotidiano, conforme o pensamento de Freedman (2001, 2003) e Duncum (2002a, 2002b). Seguindo o pensamento de Freedman (in BARBOSA, 2005), o que acontece na apropriação das visualidades é uma relação intertextual, pois o indivíduo integra imagens a seu imaginário de forma sucessiva (uma interfere na associação da outra). "Há necessariamente um confronto com uma nova forma visual, o foco da cognição costuma envolver a inter-relação entre referências dispersas da cultura visual e não de um único objeto ou significado”. (p.139)

Ainda, seguindo o pensamento de Freedman (2002, p.1): "Artes Visuais abrangem a maior parte da cultura visual, que é tudo o que é humanamente formado e sentido através da visão ou visualização e molda o modo como vivemos". Entende-se desta forma, que a subjetividade pode sugerir a compreensão que temos sobre o nosso eu e sobre o outro. Envolvendo 
pensamentos e emoções conscientes e inconscientes, que constituem nossas concepções sobre 'quem somos nós' e 'quem é o outro'. Isto estaria presente quando nos apropriamos das visualidades de forma intertextual.

É relevante que se discuta, o que é um objeto artístico e um objeto estético, já que a função da arte e o seu valor não estão em copiar a realidade, mas sim na apresentação simbólica do mundo, ou seja, seguindo o pensamento de Martins \& Aranha (1998), "a arte é um dos modos pelos quais o homem atribui sentido à realidade que o cerca, e uma forma de organização que transforma a experiência, o vivido, em objeto de conhecimento, sendo, portanto, simbólica" (p.136).

Leva-se em consideração, no atual momento que inúmeros museus e galerias expõem o que pertence ao (visual) cotidiano, presente na vida de todos nós: desde árvores natalinas, carros, frascos de perfumes, ou ainda sacolas de famosas grifes. Diante desta realidade, evidencia-se a pergunta: isto é arte?

Dessa forma, torna-se relevante o pensamento de Jan Mukarovský (1997), que coloca que a arte seria todo o texto visual que apresenta como básica a função estética, por sua vez, o objeto estético seria a imagem que tem a função estética como secundária. Assim, leva-se em consideração que uma peça de roupa descontextualizada de sua função (que é ser vestida), quando exposta em um museu ou galeria assume uma postura legítima de obra de arte, pois sua função foi deslocada.

Essa questão é ampliada, quando referimos à visibilidade do campo expandido no objeto artístico, que possibilita a consideração de diferentes práticas do artista, localizadas em relação a reflexões, que vão além da imagem apresentada. Essas relações constituem misturas intertextuais na realização do projeto plástico, que se identifica na obra, de forma a estabelecer diálogos contundentes, por meio dos conjuntos culturais. (Lembrar as obras de Claude closky, Sylvie Fleury, ou Cindy Sherman, por exemplo).

Isso evidencia um pensar que vai ultrapassar os materiais utilizados, ou seja, o que se propõe são diferentes formas de pensar sobre a obra (a imagem), que se sobrepõe a mesma. É através da linguagem inserida em um 
pensamento filosófico que acontece a articulação da relação do homem com o real, pois é dela, que o homem constrói seus significados - e confere sentido aos signos.

Deleuze (apud BASBAUM, 1995) enfatiza "que por mais que se diga o que se vê, o que se vê não se aloja jamais no que se diz" (p. 379). Pode-se entender no pensamento de Basbaum que, não há na obra uma única verdade, pois a obra se constitui de um pensamento móvel. A cada olhar, a cada palavra tecida, firmam-se diferentes verdades e conceitos. O autor nos propõe uma inversão de pensamento, que poderá ocorrer quando refletirmos sobre como acontece a leitura de um signo: desta forma, a compreensão constitui-se de múltiplos olhares móveis. Estes olhares acolhem uma multiplicidade de discursos (sociológicos, antropológicos, históricos e filosóficos), que possibilitam visibilidades ${ }^{3}$. O que se busca é a essência da obra através da compreensão, que estabeleça uma co-relação signo/sentido.

Dar visibilidade a um tema (ou a um enunciado), predispõe um olhar que vá além do 'ver' espontâneo. Acredita-se que essa seja a problemática pósmoderna: a forma como percebemos, interpretamos e compreendemos essa visibilidade impõe um pensamento crítico e reflexivo, o que na maioria das vezes é complexo, pois torna-se difícil desenvolvermos um pensamento crítico sobre a massa de imagem que nos rodeia.

Assim, a imagem de uma marca, por exemplo, constitui um cenário conceitual que atrai pelo desejo e pelas histórias que a elas são atribuídas, criando o que Semprine (apud CASTILHO, 2006, p. 46), chamou de "mundos possíveis"; um mundo real que já não atrai mais e um outro mundo possível/imaginário extremamente sedutor.

Para Debord (1997):

O princípio do fetichismo da mercadoria, a denominação da sociedade por "coisas supra-sensíveis embora sensíveis", se realiza completamente no espetáculo, no qual o mundo sensível é substituído por uma seleção de imagens que existe acima dele, e que ao mesmo tempo se fez reconhecer como o sensível por excelência. (p. 28)

\footnotetext{
${ }^{3} \mathrm{~A}$ visibilidade permite um deslocamento de tempo/espaço no olhar do espectador, desta forma torna-se visível o enunciado em um texto visual.
} 
Dessa forma, o sistema estético da moda torna-se alvo de apresentações complexas, pois personificam significados que emergem por meio de interpretações com relação do objeto que é representado e sua representação na sociedade - a imagem da moda produz manobras que conduzem a padrões de beleza idealizados e estereotipados. Por meio do interrelacionamento da imagem da moda com as Artes Visuais, ou seja, entre a cultura de massa e a Arte, novos significados (mais críticos talvez), poderão surgir. (Lembrar as performances de Beth Moyses, as obras de Nazareth Pacheco, Leonilson, Hélio Oiticica, entre outros).

Para abordar a temática da imagem da moda paralela ao Ensino da Arte é necessário partir do pensamento entre o conceito de Arte e a experiência estética no processo educacional. A contemporaneidade retoma estes conceitos imbricados a uma diversidade cultural. Assim, a recepção pode ser tida como experiência estética, não omitindo que a imagem da moda (imagens publicitárias e de propagandas), presume a legibilidade do produto. (Lembrar das campanhas publicitárias de marcas como a Benetton, ensaios fotográficos da Vogue, ou ainda, algumas temáticas da boneca Babie, por exemplo).

Pensar sobre a recepção dessas imagens sugere que a recepção seja vista como um conjunto de relações sociais e culturais mediadora da comunicação como processo social. Ou seja, é preciso entender as interpretações e o modo como o receptor/espectador/leitor elabora sua produção de sentido.

Conforme Novaes (2005), o estatuto da imagem configura-se em criar sujeitos para mercadorias, e não mais, somente mercadorias para sujeitos. Percebe-se que a identidade cultural é um processo dinâmico e está em constante re-elaboração, ou seja, transforma-se a cada momento. Dessa forma, o problema não está na imagem, "mas sim no excesso de sua produção e no novo sentido que se quer dar a elas" (p. 11). O que está sendo constituído por estas imagens? Qual o conteúdo e intenções? Estes direcionamentos estão imbricados a mensagens subliminares em publicidade e propagandas. Outro detalhe, é que hoje se consome muito mais pela forma do que pelo conteúdo. 
É preciso pensar a identidade do sujeito pós-moderno no processo comunicacional, para que não se confunda a significação da mensagem com o sentido do processo. Ou seja, pensa-se o consumo da imagem e o consumo do produto. Vale salientar que para Lipovetsky (2004), vive-se na hipermodernidade, onde tudo se torna hiper, inclusive o impulso ao consumo e a comunicação de massa.

Debord (1997) nos aponta que:

\begin{abstract}
A alienação do espetáculo em favor do objeto contemplativo (o que resulta de sua própria atividade inconsciente) se expressa assim: quanto mais ele contempla, menos vive; quanto mais aceita reconhecer-se nas imagens dominantes da necessidade, menos compreende sua própria existência e seu próprio desejo. Em relação ao homem que age, a exterioridade do espetáculo parece no fato de seus próprios gestos já não serem seus, mas de um outro que os representa por ele. (p.30)
\end{abstract}

O espetáculo institui ou propicia o deslocamento entre um sujeito ter algo e parecer algo. Alguns teóricos pensaram a constituição da construção da identidade/subjetividade do sujeito contemporâneo: Maffesoli destacou o lugar crescente de novas tribos (ou grupos) urbanos na definição do tempo/espaço; Bourdieu pesquisou sobre a desigualdade social reproduzida na cultura; Deleuze inseriu filosofia na costura dos fragmentos que falam da diferença cultural do sujeito; Foucault fala do saber social construído em micro unidades da vida social e Guattari inter-relacionou a psicanálise e a tecnologia como eixos explicativos das formas contemporâneas.

Para Martín-Barbero (1995), a recepção é permeada por uma investigação conceitual: passa pelos estudos da vida cotidiana do sujeito (seus conceitos de ruptura), pelos estudos do consumo, pela pesquisa semântica da leitura e pelo estudo da história sociocultural dos gêneros. Seguindo este pensamento, ente autor diz que o consumo poderá ser visto como prática de apropriação dos produtos sociais - não como um simulacro baudrillardiano, pois: "em nossa sociedade há simulacro, mas também há divisão social e diferentes modos de apropriar-se dos produtos" (p. 61), ou seja, para sair da discussão do simulacro e adentrar na investigação do consumo, é preciso olhar para 'este consumo' como uma prática de apropriação dos produtos sociais. $\mathrm{O}$ DAPesquisa, Florianópolis, v.2, n.4, p. 187-196, 2007. 
consumo é o lugar da diferenciação social. É o lugar da distinção simbólica, não só pelo fato do consumo material, mas pela forma 'como' se consome.

O consumo também pode ser tido como um sistema de integração e de comunicação de sentidos, conforme Martín-Barbero (1995), é o lugar/brecha ou dobra de circulação do sentido. Consumir equivale-se a representações de cenários de objetivações dos desejos individuais - consumir tem organização e lógica dentre os diferentes grupos sociais.

Imagens são elaborações repletas de significados, que dependem tacitamente de interações sociais que não operam em linearidades. Assim, há necessidade de buscar tessituras que levem o receptor a uma alfabetização visual.

É necessário que se pense na recepção da imagem e no tempo de sua produção. A forma como o leitor compreende e apreende seus significados, se isso realmente acontece ou não, e além, se a imagem significa algo para a complexa formação da identidade do receptor. A moda pode ser vista como um objeto problematizador de tudo e de todos em uma sociedade permeada pelo espetáculo. Segundo Debord (1997), a sociedade do espetáculo não se configura apenas pelas imagens, mas leva-se em consideração, as relações sociais mediadas pelas imagens - é isto que está além do espetáculo.

Esse é o contexto da sociedade que perpassa o olhar do professor de Artes Visuais. É na escola ou em grupos de jovens que as identidades se constroem. O professor não deverá fechar os olhos para esta realidade e transformar-se em mero transmissor ou repassador de conteúdos. A moda produz uma imagem que assume condições expressivas de serem analisadas e pensadas em consonância com o conteúdo de arte.

Busca-se um olhar crítico-estético, que perpasse pela educação e, desta forma, a aproximação da arte em relação à moda pode tangenciar uma educação para a compreensão crítica da arte. Acredita-se em uma educação que produza, que construa conhecimento significativo e não em uma educação que repasse, que vise a memorização ou ainda, a formação do indivíduo em fôrmas e formas idênticas - a mesma educação propõe mundos distintos. É necessário que o professor pense qual realidade ele quer propor para seus

DAPesquisa, Florianópolis, v.2, n.4, p. 187-196, 2007. 
alunos. De modo que compreenda os resultados de suas escolhas. É deste pensamento que nasce a tessitura de um olhar crítico.

Não se trata de equiparar as áreas de conhecimento, apenas pensar nas proximidades. Assim, entende-se que os estudos culturais podem considerar/embasar estas proximidades entre Artes visuais, a Imagem da moda, a cultura visual e a sociedade em que vivemos. Para Stuart Hall (2000), a perspectiva dos estudos culturais pode levar a pensar uma teoria da identidade coletiva, na qual possamos ir além das posições discretas sobre a diferença e recusar os modos de representação em crise enquanto trabalhamos para construir comunidades mais humanitárias (JAMENSON, 1998).

Fazem parte da discussão sobre os estudos culturais o questionamento científico, a análise da produção de significados nos mais diferentes artefatos, a discussão das identidades e subjetividades do homem contemporâneo, assim como as tendências interculturais e hibridas.

Como forma de abordagem transmetodológica os estudos culturais pressupõe a etnografia (usada para analisar as formas de vida dos grupos populares e experiências de diferenças culturais), e as análises discursivas ou textuais (voltada para análise de diferentes artefatos). Buscar a compreensão crítica e reflexiva do contexto midiático dos meios de comunicação e a forma como significamos ao que a mída divulga e produz faz parte dos estudos culturais contemporâneos.

A arte, na perspectiva dos Estudos Culturais, são representações sociais, portanto, constitutivas de visões de mundo de determinados grupos sociais conforme Franz (2003) e Hernandez (2000). Assim, os professores de Artes Visuais, poderão compreender a arte baseado-se em movimentos e agenciamentos culturais.

DAPesquisa, Florianópolis, v.2, n.4, p. 187-196, 2007. 


\section{Referências Bibliográficas:}

BARBOSA, Ana Mae (Org). Arte/educação contemporânea: consonâncias internacionais. São Paulo: Cortez, 2005.

BASBAUM, Ricardo. "Migrações das palavras para a imagem" in Revista Gávea 13. PUC - RJ, 1995. (págs. 373-394)

CASTILHO, Kathia; VILLAÇA, Nízia (Orgs). O novo luxo. São Paulo: Anhembi Morumbi, 2006.

DEBORD, Guy. A sociedade do espetáculo. Rio de Janeiro: Contraponto, 1997. DUNCUM, P. Clarifying visual culture art education. Art Education, 2002a, v.55, n.3, págs. 6-11.

Visual culture art education: why, what and how. Journal of Art \& Design Education, 2002b, v.21, n.1, págs. 14-24.

FRANZ, Teresinha Sueli. Educação para compreensão crítica da arte.

Florianópolis: Letras Contemporâneas, 2003.

Arte, educação e identidade: entrelaçamentos culturais e sociais desafios para uma arte-educadora pós-moderna In Anais $17^{\circ}$ seminário nacional de Arte e Educação. Montenegro: Ed. Fundarte, 2003.

FREEDMAN, kerry; HERNÁNDEZ, Fernando. Curriculum, culture and art education., New York: Suny press, 1998.

. "Currículo dentro e for a da escola: representações da arte na cultura visual. In: BARBOSA, Ana Mae (Org.) Arte/educação contemporânea: consonâncias internacionais. São Paulo: Cortez, 2005.

. Social perspective on art education in the U. S.: teaching visual culture in a democracy. Studies in Art Education, 2001, v.41, n. 4. Págs.314 à 329

. Teaching visual culture: curriculum aesthetics and the social life of art. New York: Teachers College Press, 2003.

HALL, Stuart. A identidade cultural na pós-modernidade. Rio de Janeiro: DP\&A, 2003.

Los estudios culturales y sus legados teóricos: genealogía de un proyecto abierto. Voces y Cultura, 16. Barcelona (2000).

DAPesquisa, Florianópolis, v.2, n.4, p. 187-196, 2007. 
HERNÁNDEZ, Fernando. Cultura visual, mudança educativa e projeto de trabalho. São Paulo: Artmed, 2000.

JAMESON, Frederic. Sobre los Estudios Culturales In: JAMENSON, F. e ZIZEK,

S. Estudios Culturales : Reflexiones sobre el multiculturalismo. Argentina:

Paidós, 1998.

LIPOVETSKY, Giles. Os tempos hipermodernos. São Paulo: Barcarolla, 2004. MARTIN-BARBERO. América latina e os anos recentes: estudo de recepção em comunicação social. In: SOUZA, Mauro W. (Org.) Sujeito, o lado oculto do receptor. São Paulo: Editora Brasiliense, 1995. Pág 39 à 68 MARTINS, Maria Helena; ARANHA, Maria L. de Arruda. Temas de filosofia. São Paulo: Editora Moderna, 1998.

NOVAES, Adauto (Org.). Muito além do espetáculo. São Paulo: Editora $S$ MUKAROVSKÝ, Jan. Escritos sobre estética e semiótica da arte. Lisboa: Editora Estampa, 1997. 